\title{
Does the orthodontic technique employed lend a specific conformation to the post-treatment arch form? A comparison of the Tweed and Damon therapies*
}

\author{
Mathilde Galievsky \\ Directeur de mémoire : Alain DECKER / Paris \\ Co-directeur de mémoire : Xavier PENIN
}

ABSTRACT

Does the technique employed create a specific post-treatment arch form? To answer this question we compared the arches at the close of treatment of patients treated by the Tweed technique with those treated by the Damon technique. We analyzed 78 plaster models using the computer program. Procluso in an attempt to standardize assessment of the arch forms. The post-treatment arch form surimposition showed no differences between arches of patients treated by Tweed therapy and arches of patients treated by Damon technique. Regression and discrimination tests were used in order to calculate and visualize singles differences in form between the three samples used in our study (patients treated by Tweed therapy without extraction, patients treated by Tweed therapy with extractions and patients treated by Damon therapy without extractions). This is the outcome of differences located at the level of position of teeth related to the shape of dental arch form. On the other hand dental arch forms are nearly similar in the various samples. Arch form was just more harmonious, more well rounded with good continuity of buccal surfaces when practitioners used pre-adjusted Damon brackets compared to braces with no built-in torque employed in Tweed therapy.

\section{KEYWORDS \\ Arch form \\ Tweed technique \\ Damon technique \\ Edgewise technique \\ Self-ligating}

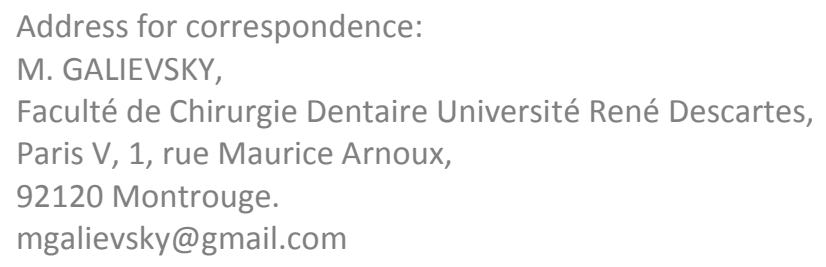

* The English version of this paper is not available; to read the French version, go to http://odf.edpsciences.org/10.1051/odf/2009001 